\title{
Dental visit patterns and periodontal treatment needs among Saudi students
}

J.M.A. Farsi'

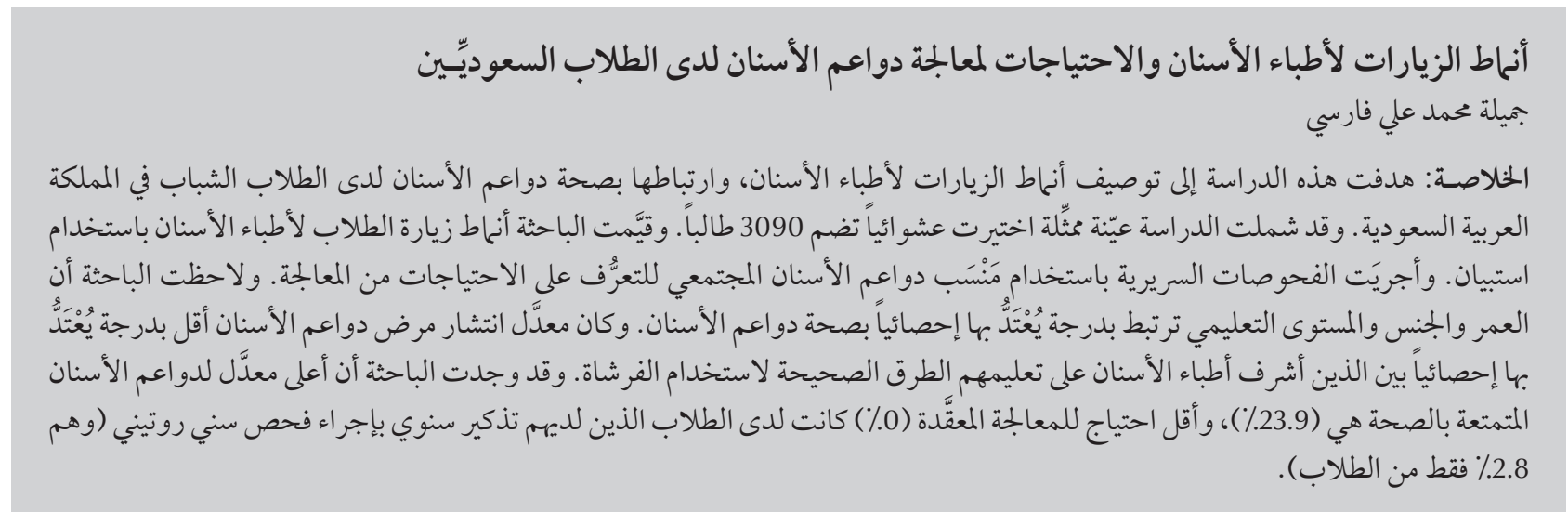

ABSTRACT The aim of this study was to report on dental visit patterns and their association with periodontal health among young Saudi Arabian students. A representative sample of 3090 students was randomly selected. The students' dental visit patterns were assessed with a questionnaire. Clinical examinations were carried out using the community periodontal index of treatment needs. Age, sex and education level were significantly associated with the periodontal health. The prevalence of periodontal disease was significantly lower among subjects who were taught the right way to brush their teeth by the dentist. The highest occurrence of healthy periodontium (23.9\%) and the lowest need for complex treatment $(0 \%)$ were found among students who had annual reminders for check-ups (only $2.8 \%$ of the students).

\section{Habitudes de consultation dentaire et besoins en traitements parodontaux chez des étudiants saoudiens}

RÉSUMÉ L'objectif de cette étude était de décrire les habitudes de jeunes étudiants saoudiens en matière de consultations dentaires et leur association avec la santé parodontale. Un échantillon représentatif de 3090 étudiants a été sélectionné de manière aléatoire. Leurs habitudes de consultation dentaire ont été évaluées au moyen d'un questionnaire. Des examens cliniques ont été réalisés à l'aide de l'indice des besoins de la collectivité en matière de traitement des parodontopathies. L'âge, le sexe et le niveau d'instruction étaient associés de manière significative avec la santé parodontale. La prévalence des parodontopathies était sensiblement plus basse chez les sujets à qui leur dentiste avait appris à se brosser correctement les dents. La fréquence la plus élevée de ligaments alvéolo-dentaires sains $(23,9 \%)$ et le besoin de traitement complexe le plus faible $(0 \%)$ ont été relevés chez les étudiants qui recevaient des rappels annuels au sujet de leur bilan périodique (2,8\% des étudiants seulement). 


\section{Introduction}

Personal oral hygiene routines are important at an individual level to maintain oral health. Equally important are regular dental visits, as they provide professional diagnostic and prophylactic services that are essential to prevent periodontal disease $[1,2]$. The percentage of individuals who report having visited the dentist the preceding year varies between studies in different countries [1,3-5]. As for gender, literature from several countries reported differences in oral health behaviour between males and females. In some studies, females visited dentists and used oral hygiene tools more frequently than males [4-8], whereas other studies did not find such a gender difference $[3,9]$. Various studies showed an association between the utilization of dental services and oral health $[1,10,11]$.

This research is part of a larger study of the epidemiology of periodontal disease among the young Saudi Arabian population. The aims of this study were to assess the association between periodontal health status and dental visit patterns, and to identify the reasons for visiting or not visiting the dentist among students aged 11-24 years in Jeddah.

\section{Methods}

\section{Study design and sample}

This was a cross-sectional study conducted in Jeddah, the second largest city in Saudi Arabia and the largest city in Western province. The target population was middle-school, high-school and university students, aged 11-24 years old and resident in Jeddah city.

Prior to the study, a pilot study was carried out on a sample of 50 students to determine the sample size and test the questionnaire. Sampling was performed to select a population representative of young adults in the city and provide sufficient power to detect differences in periodontal disease where it existed. A sample size of 3100 Saudi Arabian students was selected based on the Lemeshow formula [12].

A complete list of middle schools and high schools was obtained from the Ministry of Education. Schools were stratified according to sex (male and female), source of funding (private and public) and 6 geographic locations. Schools were then selected randomly from each stratum by proportional allocation; 21 middle schools (15 public and 6 private) and 14 high schools (10 public and 4 private) were included, out of a total of 260 middle and 210 high schools. Students from 8 colleges ( 4 female and 4 male) were selected, also using the proportional allocation technique.

\section{Questionnaire}

The questionnaire used in the study included questions about demographic factors, dental visits, the reasons for visiting or not visiting the dentist and some signs of oral health conditions that might be noticed by the subjects.

The response rate was $97.5 \%$, as the questionnaire was distributed to 3200 subjects and returned by 3122 . Questionnaires were administered and collected in class by one of the dentists. The anonymity of participants was emphasized.

\section{Clinical examination}

Examinations were conducted in classrooms by calibrated dentists. A lightweight portable examination light was used, and subjects were positioned so as to receive maximum illumination. Plane mouth mirrors and standard probes were used to conduct the examinations. Teeth were examined using the community periodontal index of treatment needs (CPITN) procedure of the World Health Organization (WHO) [13]. Teeth were examined in the following sequence: upper right sextant, upper anterior sextant, upper left posterior sextant, lower left posterior sextant, lower anterior sextant and lower right posterior sextant. For each of the 6 sextants examined, a code from 0 to
4 was given according to the following clinical criteria: (0) healthy gingiva; (1) bleeding observed directly or by using mouth mirror; (2) calculus felt during probing, but black areas of the probe were visible ( $3.5-5.5 \mathrm{~mm}$ from ball tip); (3) a pocket of 4 or $5 \mathrm{~mm}$, the gingival margin was situated on the black area of the probe (3.5-5.5 $\mathrm{mm}$ form the probe tip); and (4) a pocket of $>6 \mathrm{~mm}$, black area of the probe not visible. Based on the clinical findings, each subject was categorized into 1 of 4 treatment groups on the basis of the most severe condition found. The 4 treatment categories were as follows: no treatment (code 0 ); improved oral hygiene (code 1); improved oral hygiene and scaling (codes $2 \& 3$ ); and improved oral hygiene and complex treatment (code 4).

Prior to the study, 6 dentists were trained at King Abdulaziz University dental clinics, and the kappa statistics among the examiners for the CPITN were calculated. Examinations for CPITN among 50 students gave an inter-examiner kappa value of 0.65 and an intra-examiner kappa value of 0.72 .

A total of 3090 students were examined according to the above methods.

\section{Statistical analysis}

Data were processed and analysed using the statistical package SPSS, versions 13 and 16. Descriptive statistics, including frequency and percentages, were used. Two-sided likelihood ratio chi-squared tests were used to test associations between the dependent variable and the independent variables. The level of significant was set at 0.05 .

\section{Results}

\section{Description of the study population}

The study sample consisted of 3090 students aged 11-24 years, 1281 aged $11-15,1091$ aged $16-19$ years and 670 aged $20-24$ years. Of these, $56.8 \%$ were females and $43.2 \%$ were males. 


\section{Periodontal status}

The association between CPITN and students' age, education level and sex is shown in Table 1. Age, sex and education level were significantly associated with periodontal health status $(P<0.001)$. Approximately $20 \%$ of the $11-15$ year age group and $10 \%$ of the 20-24 year age group had healthy periodontium. Over half the males (58.0\%) and females (53.9\%) had calculus.

The prevalence of periodontal disease increased significantly with age in both sexes $(P<0.001)$.

\section{Dental visits and CPITN}

Table 2 shows the relationship between the periodontal health of students and dental visits. Of the students $22.6 \%$ had never visited the dentist and $61.8 \%$ of them needed scaling; in contrast, among the majority of students who had ever visited the dentist, 54.3\% needed scaling. Among participants who reported that they had not visited the dentist within the past year, 59.0\% needed scaling.

The prevalence of periodontal disease was significantly lower among the subjects who reported that they had been taught the right way to brush their teeth by the dentist (18.0\% had healthy periodontium and $51.1 \%$ needed scaling), while among the rest of the students, $14.5 \%$ had healthy periodontium and $59.3 \%$ needed scaling.

\section{Dental visits by students' sex}

Significantly more females (61.2\%) had visited the dentist during the previous year than had males (55.9\%). In addition, more females than males had been taught the right way to brush their teeth by their dentist $(P<0.001)$ (Table 3).

\begin{tabular}{|c|c|c|c|c|c|c|c|}
\hline \multirow[t]{3}{*}{ Demographic characteristic } & \multirow{2}{*}{\multicolumn{2}{|c|}{ Total students ${ }^{\mathrm{a}}$}} & \multirow{2}{*}{\multicolumn{4}{|c|}{$\begin{array}{l}\% \text { of students } \\
\text { CPITN score }\end{array}$}} & \multirow[t]{3}{*}{$P$-value ${ }^{b}$} \\
\hline & & & & & & & \\
\hline & No. & $\%$ & $\mathbf{0}$ & 1 & 2 & 3 & \\
\hline \multicolumn{8}{|l|}{ Age (years) } \\
\hline $11-15$ & 1281 & 42.1 & 20.5 & 31.8 & 46.8 & 0.9 & \multirow{3}{*}{$<0.001$} \\
\hline $16-19$ & 1091 & 35.9 & 14.2 & 23.6 & 60.6 & 1.6 & \\
\hline $20-24$ & 670 & 22.0 & 10.3 & 16.9 & 65.7 & 7.2 & \\
\hline \multicolumn{8}{|l|}{ Sex } \\
\hline Male & 1267 & 43.2 & 22.3 & 17.7 & 58.1 & 1.9 & \multirow[t]{2}{*}{$<0.001$} \\
\hline Female & 1656 & 56.8 & 11.1 & 31.8 & 54.1 & 3.0 & \\
\hline \multicolumn{8}{|l|}{ Education level } \\
\hline Middle & 1420 & 47.9 & 19.6 & 30.3 & 49.2 & 1.0 & \multirow{3}{*}{$<0.001$} \\
\hline Secondary & 871 & 29.4 & 14.9 & 23.5 & 60.7 & 0.8 & \\
\hline University & 671 & 22.7 & 10.3 & 17.9 & 63.9 & 7.9 & \\
\hline
\end{tabular}

${ }^{a}$ Numbers do not add up due to missing data. ${ }^{b}$ Chi-squared test.

\begin{tabular}{|c|c|c|c|c|c|c|c|}
\hline \multirow[t]{3}{*}{ Dental visit } & \multirow{2}{*}{\multicolumn{2}{|c|}{ Total students }} & \multirow{2}{*}{\multicolumn{4}{|c|}{$\begin{array}{l}\% \text { of students } \\
\text { CPITN score }\end{array}$}} & \multirow[t]{3}{*}{$P$-value ${ }^{\text {a }}$} \\
\hline & & & & & & & \\
\hline & No. & $\%$ & $\mathbf{0}$ & 1 & 2 & 3 & \\
\hline \multicolumn{8}{|c|}{ I have visited the dentist } \\
\hline Yes & 2337 & 77.4 & 16.5 & 26.7 & 54.3 & 2.6 & \multirow{2}{*}{0.005} \\
\hline No & 684 & 22.6 & 14.6 & 21.3 & 61.8 & 2.2 & \\
\hline \multicolumn{8}{|c|}{ I visited the dent ist last year } \\
\hline Yes & 1768 & 58.9 & 15.8 & 27.7 & 53.8 & 2.7 & \multirow{2}{*}{0.007} \\
\hline No & 1236 & 41.1 & 16.4 & 22.3 & 59.0 & 2.3 & \\
\hline \multicolumn{8}{|c|}{$\begin{array}{l}\text { The dent ist taught me the right way } \\
\text { to brush teeth }\end{array}$} \\
\hline Yes & 1182 & 39.0 & 18.0 & 29.1 & 51.1 & 1.6 & \multirow{2}{*}{$<0.001$} \\
\hline No & 1845 & 61.0 & 14.5 & 23.2 & 59.3 & 3.0 & \\
\hline
\end{tabular}

${ }^{a}$ Chi-squared test. 


\begin{tabular}{|c|c|c|c|c|c|}
\hline \multirow[t]{3}{*}{ Dental visit } & \multicolumn{4}{|c|}{ Sex } & \multirow[t]{3}{*}{$P$-value ${ }^{\text {a }}$} \\
\hline & \multicolumn{2}{|c|}{ Male } & \multicolumn{2}{|c|}{ Female } & \\
\hline & No. & $\%$ & No. & $\%$ & \\
\hline \multicolumn{6}{|c|}{ I have visited the dentist } \\
\hline Yes & 960 & 74.7 & 1333 & 79.9 & \multirow[t]{2}{*}{$<0.001$} \\
\hline No & 326 & 25.3 & 335 & 20.1 & \\
\hline \multicolumn{6}{|c|}{ I visited the dent ist last year } \\
\hline Yes & 715 & 55.9 & 1014 & 61.2 & \multirow{2}{*}{0.002} \\
\hline No & 565 & 44.1 & 644 & 38.8 & \\
\hline \multicolumn{6}{|c|}{ The dent ist taught me the right way to brush teeth } \\
\hline Yes & 466 & 36.6 & 669 & 40.1 & \multirow{2}{*}{$<0.001$} \\
\hline No & 808 & 63.4 & 998 & 59.9 & \\
\hline
\end{tabular}

${ }^{a}$ Chi-squared test.

\section{Reasons for dental visits and CPITN}

Pain and dental problems were the most common reason to visit the dentist, followed by random check-ups (Table 4). The subjects who were reminded of the annual visit by their dentist had the highest occurrence of healthy periodontium (23.9\%) and none needed complex oral treatment (Table 4).

\section{Reasons for not visiting the dentist and CPITN}

As shown in Table 5, the most common cause for not visiting the dentist was the feeling of having no need for a dental visit, followed by the fear of pain and not having the time to do so. There was a significant relationship between the periodontal health of students and the reasons they stated for not visiting the dentist. The students who stated that there was no need for dental visits had the highest percentage of healthy periodontium (21.9\%) and lowest percentage for needing complex treatment (0.9\%).

\section{Discussion}

This is the first study to explore the relationship between dental visit patterns and periodontal health in a representative sample of the young Saudi Arabian population. The almost universal occurrence of dental calculus in young populations suggests inadequate oral hygiene practices and other unhealthy dental behaviours. In the present study, the presence of calculus was the most common periodontal condition in both sexes and all age groups. This was similar to most studies in the regions and elsewhere [14-16], but different from another study in Saudi Arabia [17]. In addition, calculus was present in more males than females, in agreement with studies from other countries $[7,18,19]$.

In this study, around $60 \%$ of individuals had visited the dentist in the previous year, $8.6 \%$ had received regular check-ups and only $2.8 \%$ were reminded of annual check-ups by the dentist. In contrast, in Sweden, 90\%-95\% of all individuals visited the dentist on a regular basis every year or every other year, and about $70 \%-80 \%$ of all adults were enrolled in a recall system on the dentist's initiative [19]. Also in the USA, Dye and Selwitz reported that around $70 \%$ of subjects had visited the dentist within the past 12 months [1]. A study

\begin{tabular}{|c|c|c|c|c|c|c|}
\hline \multirow[t]{3}{*}{ Reason for dental visit } & \multirow{2}{*}{\multicolumn{2}{|c|}{ Total students }} & \multirow{2}{*}{\multicolumn{4}{|c|}{$\begin{array}{l}\% \text { of stuents }{ }^{\mathrm{a}} \\
\text { CPITN score }\end{array}$}} \\
\hline & & & & & & \\
\hline & No. & $\%$ & $\mathbf{0}$ & 1 & 2 & 3 \\
\hline Pain and dental problems & 1179 & 49.4 & 15.0 & 26.5 & 56.1 & 2.4 \\
\hline Random check-up & 399 & 16.7 & 18.3 & 26.1 & 52.4 & 3.3 \\
\hline Regular check-up & 205 & 8.6 & 22.0 & 33.2 & 43.9 & 1.0 \\
\hline Gingival problems & 171 & 7.2 & 8.2 & 23.4 & 66.7 & 1.8 \\
\hline Dentist reminder of annual visit & 67 & 2.8 & 23.9 & 37.3 & 38.8 & 0.0 \\
\hline 2 reasons & 315 & 13.2 & 13.0 & 27.6 & 56.2 & 3.2 \\
\hline $3+$ reasons & 50 & 2.1 & 26.0 & 34.0 & 38.0 & 2.0 \\
\hline
\end{tabular}

${ }^{a} P<0.001$. 


\begin{tabular}{|c|c|c|c|c|c|c|}
\hline \multirow[t]{3}{*}{ Reason for not visiting the dentist } & \multicolumn{2}{|c|}{ Total students } & \multirow{2}{*}{\multicolumn{4}{|c|}{$\begin{array}{c}\% \text { of students } \\
\text { CPITN score }\end{array}$}} \\
\hline & \multirow[b]{2}{*}{ No. } & & & & & \\
\hline & & $\%$ & 0 & 1 & 2 & 3 \\
\hline No need for dental visits & 647 & 28.7 & 21.9 & 23.6 & 53.5 & 0.9 \\
\hline Fear of pain & 556 & 24.7 & 12.9 & 25.2 & 59.2 & 2.7 \\
\hline Do not have time & 385 & 17.1 & 13.5 & 25.5 & 58.4 & 2.6 \\
\hline Difficulty making an appointment & 121 & 5.4 & 13.2 & 21.5 & 63.6 & 1.7 \\
\hline Difficulty reaching the dental clinic & 78 & 3.5 & 16.7 & 26.9 & 50.0 & 6.4 \\
\hline Expensive treatment fees & 68 & 3.0 & 16.2 & 20.6 & 58.8 & 4.4 \\
\hline 2 reasons & 322 & 14.3 & 10.6 & 23.3 & 63.7 & 2.5 \\
\hline $3+$ reasons & 75 & 3.3 & 13.3 & 20.0 & 62.7 & 4.0 \\
\hline
\end{tabular}

${ }^{a} p<0.001$.

conducted in California found that $66 \%$ reported visiting the dentist in the preceding year. About $41 \%$ said that getting a regular check-up was their main reason for the last dental care visit, and this percentage was higher in females than males [5]. A study in Michigan found a much higher percentage of regular visits, where $75 \%$ of subjects reported having a dental check-up at least once a year [20]. On the other hand, in Uganda only $21 \%-37 \%$ of the population has ever visited a dentist [21], and 44\% received dental care in the past 2 years [22]. Similar to our results, other studies reported that females use dental services more regularly than males $[4,6,23,24]$. Others found no difference in dental behaviour between males and females $[3,9]$.

In our study, the most common reason for visiting the dentist was pain and dental problems (49.9\%). The regular check-up as a reason for visiting the dentist accounted for $8.6 \%$, and reason for visits due to dentist reminders accounted for only $2.8 \%$. Almas et al. in Saudi Arabia reported that $67 \%$ of males and $59 \%$ of females visited dentists only when in pain [25]. Similarly, in Jordan, male students visited the dentist only when in pain [4]. In contrast, in Finland, the most common reason for the most recent dental visit was a routine examination [24]. As for reasons for not visiting the dentist, our study found that feeling that there was no need for a dental visit was the most common reason, followed by the fear of pain.

Our study showed an association between the utilization of dental services and periodontal health, especially if the dental visit was due to a reminder by the dentist or the patient was given oral hygiene instructions (i.e. taught how to brush by the dentist). The study also showed a very low percentage of regular annual visits in this group, which indicates a need to emphasize the importance of regular dental visits in addition to a better recall system by dentists.

The CPITN was endorsed by the WHO for population-based surveys in the 1980s. Although it has limitations, CPITN reflects unmet treatment needs and can give a fair assessment of the periodontal condition. It was used in this study because it has proved to be a simple and effective method for measuring and monitoring the severity of periodontal disease at the community level [26].

There are some limitations to our study. First, we used self-reported data. Such data may be less accurate than data collected by observation or examination. Measurementerror due to misinterpretation of questions and memory error may occur [27]. To overcome this problem, a pilot study was performed, and the questions were worded as simply as possible. As a cross-sectional study design, inferences cannot be drawn about the casual relationship between the risk indicators and periodontal disease. Nonetheless we were able to show a significant association between the periodontal health of students and the reasons they gave for not visiting the dentist.

Knowledge about the epidemiology of periodontal disease in Saudi Arabia will help to establish baseline data about dental health needs. The importance of the utilization of dental services should be emphasized through various channels, including schools, mass media and the oral health providers themselves. Schools provide a unique setting to develop awareness of the importance of regular dental visits. To help individuals and group advocates of health promotion in schools, the WHO has produced a programme "Information services on school health" [28]. The experiences of systemic oral health care programmes in some Middle Eastern countries should also be considered $[3,29]$.

\section{Acknowledgements}

This study was financially supported by King Abdulaziz University, Grant No. 015/415. The author acknowledges Professor Mahassen Farghaly and Dr Ahmed Bahnasy for their contribution to the study design and sampling, Dr Soleman Mirdad for the statistical analysis, and Dr Leena Merdad for reviewing the manuscript. 


\section{References}

1. Dye BA, Selwitz RH. The relationship between selected measures of periodontal status and demographic and behavioura risk factors. Journal of Clinical Periodontology, 2005, 32(7):798808.

2. Satcher D. Oral health in America: a report of the Surgeon General. Rockville, Maryland, National Institutes of Health, US Department of Health and Human Services, 2000.

3. Rajab LD et al. Oral health behaviour of schoolchildren and parents in Jordan. International Journal of Paediatric Dentistry, 2002, 12(3):168-176.

4. Al-Omari QD, Hamasha AA. Gender-specific oral health attitudes and behavior among dental students in Jordan. Journal of Contemporary Dental Practice, 2005, 6(1):107-114

5. Tomar SL, Azevedo AB, Lawson R. Adult dental visits in California: successes and challenges. Journal of Public Health Dentistry, 1998, 58(4):275-280.

6. Behbehani JM, Shah NM. Oral health in Kuwait before the Gulf War. Medical Principals and Practice, 2002, 11(Suppl. 1):36-43.

7. Albandar JM. Global risk factors and risk indicators for periodontal diseases. Periodontology 2000, 2002, 29:177-206.

8. Albandar JM. Periodontal diseases in North America. Periodontology 2000, 2002, 29:31-69.

9. Tseveenjav B, Vehkalahti M, Murtomaa H. Preventive practice of Mongolian dental students. European Journal of Dental Education, 2002, 6(2):74-78.

10. Morris AJ, Steele J, White DA. The oral cleanliness and periodontal health of UK adults in 1998. British Dental Journal, 2001, 191(4):186-192.

11. Brennan DS, Spencer AJ, Roberts-Thomson KF. Periodontal disease among 45-54 year olds in Adelaide, South Australia. Australian Dental Journal, 2007, 52(1):55-60.

12. Levy PS Lemeshow S. Sampling for health professionals. Belmont, California, Lifetime Learning Publications, 1980.

13. Cutress TW, Ainamo J, Sardo-Infirri J. The community peri odontal index of treatment needs (CPITN) procedure for population groups and individuals. International Dental Journal, 1987, 37(4):222-233.

14. Khader YS. Factors associated with periodontal diseases in Jordan: principal component and factor analysis approach. Journal of Oral Science, 2006, 48(2):77-84.

15. Farsi $\mathrm{N}$ et al. Periodontal health and its relationship with salivary factors among different age groups in a Saudi population. Oral Health and Preventive Dentistry, 2008, 6(2):147-154.

16. Albandar JM. Epidemiology and risk factors of periodontal diseases. Dental Clinics of North America, 2005, 49(3):517-532, $\mathrm{v}-\mathrm{vi}$.
17. Guile EE A, Al-Shammary, El-Backly M. Prevalence and severity of periodontal diseases in Saudi Arabian schoolchildren aged 6, 9 and 12 years. Community Dental Health, 1990, 7(4):429432.

18. Olsson B. Efficiency of traditional chewing sticks in oral hygiene programs among Ethiopian schoolchildren. Community Dentistry and Oral Epidemiology, 1978, 6(3):105-109.

19. Hugoson A et al. Oral health of individuals aged 3-80 years in Jonkoping, Sweden during 30 years (1973-2003). I. Review of findings on dental care habits and knowledge of oral health. Swedish Dental Journal, 2005, 29(4):125-38.

20. Lang WP, Farghaly MM, Ronis DL. The relation of preventive dental behaviors to periodontal health status. Journal of Clinical Periodontology, 1994, 21(3):194-198.

21. Kiwanuka SN, Astrom AN, Trovik TA. Dental caries experience and its relationship to social and behavioural factors among 3-5-year-old children in Uganda. International Journal of Paediatric Dentistry, 2004, 14(5):336-346

22. Okullo I, Astrom AN, Haugejorden O. Social inequalities in oral health and in use of oral health care services among adolescents in Uganda. International Journal of Paediatric Dentistry 2004, 14(5):326-335.

23. Farsi JM, Farghaly MM, Farsi N. Oral health knowledge, attitude and behaviour among Saudi school students in Jeddah city. Journal of Dentistry, 2004, 32(1):47-53.

24. Murtomaa $\mathrm{H}$, Metsaniitty M. Trends in toothbrushing and utilization of dental services in Finland. Community Dentistry and Oral Epidemiology, 1994, 22(4):231-234.

25. Almas $\mathrm{K}$ et al. The knowledge and practices of oral hygiene methods and attendance pattern among school teachers in $\mathrm{Ri}$ yadh, Saudi Arabia. Saudi Medical Journal, 2003, 24(10):10871091.

26. Senna A et al. Socio-economic influence on caries experience and CPITN values among a group of Italian call-up soldiers and cadets. Oral Health and Preventive Dentistry, 2005, 3(1):39-46.

27. Schwarz N. Assessing frequency reports of mundane behaviours: contribution of cognitive psychology to questionnaire constructions cited. In: Hendinck C, Clark MS, eds. Research methods in personality and social psychology. Beverly Hills, California, Sage Publications, 1990:98-119.

28. Petersen PE. Challenges to improvement of oral health in the 21st century: the approach of the WHO Global Oral Health Programme. International Dental Journal, 2004, 54(6 Suppl. 1):329-343.

29. Vigild $M$ et al. An oral health programme for schoolchildren in Kuwait 1986-97. Community Dental Health, 1999, 16(2):102 106. 